\title{
Reconstruction of sacral defects following necrosis of buttocks due to embolization of internal iliac artery using a transverse lumbar flap
}

Chenicheri Balakrishnan MD, Justin Yovino MD, Peter D Adams BS, Anila Balakrishnan BS, Payam Jarrahnejad MD

C Balakrishnan, J Yovino, PD Adams, A Balakrishnan, P Jarrahnejad. Reconstruction of sacral defects following necrosis of buttocks due to embolization of internal iliac artery using a transverse lumbar flap. Can J Plast Surg 2009;17(3):e8-e10.

Fractures of the pelvis associated with uncontrollable hypotension are managed by stabilization of fractures and arteriographic embolization of the bleeding vessels. Embolization of these arteries may result in necrosis of the buttocks. The use of a transverse lumbar artery-based flap can be used for repair of these defects.

Key Words: Transverse lumbar flap

T rauma patients with pelvic fractures and retroperitoneal bleeding from pelvic vessels are managed with angiographic localization and embolization of massively bleeding arterial vessels. Although there may be underlying skin contusions associated with the injury itself, buttock skin necrosis can occur from selective embolization of the internal iliac artery. We report two cases of buttock skin necrosis following transarterial embolization for control of bleeding from a pelvic fracture. The defect was repaired using a transverse lumbar flap in both patients.

\section{CASE PRESENTATIONS}

Case 1

A 64-year-old man sustained a crush injury to his pelvis following a fall from his tractor. He was unconscious with a closed head injury, and was intubated to protect his airway. His past medical history was significant for hypertension, myocardial infarction and type II diabetes mellitus. Because he was hypotensive, he underwent selective arteriography and embolization. He had a suprapubic catheter placed for a urethral injury. His general condition improved over the first $48 \mathrm{~h}$ but he developed necrosis of the buttocks (Figure 1). He underwent multiple debridements (Figure 2). Options of closure were explained to him as well as management of his pelvic fracture. He decided to undergo conservative management with external fixation for the pelvic fracture, colostomy and vacuumassisted wound closure. The wound was slow to heal, and six months later it was decided to reconstruct the defect. Because the defect was across the sacrum, a decision was made to close the defect using a transverse lumbar flap (Figure 3). The wound was debrided and flap elevated and transposed to cover the defect (Figures 4 and 5). The donor site was skin grafted and the wound healed satisfactorily (Figure 6).

\section{La reconstruction d'anomalies sacrées après une nécrose des fesses causée par une embolisation de l'artère iliaque interne, au moyen d'un lambeau lombaire transverse}

Les fractures du bassin associées à une hypotension incontrôlable sont prises en charge par la stabilisation des fractures et une embolisation artériographique des vaisseaux hémorragiques. L'embolisation de ces artères peut provoquer une nécrose des fesses. Un lambeau artériel lombaire transverse peut permettre de réparer ces anomalies.

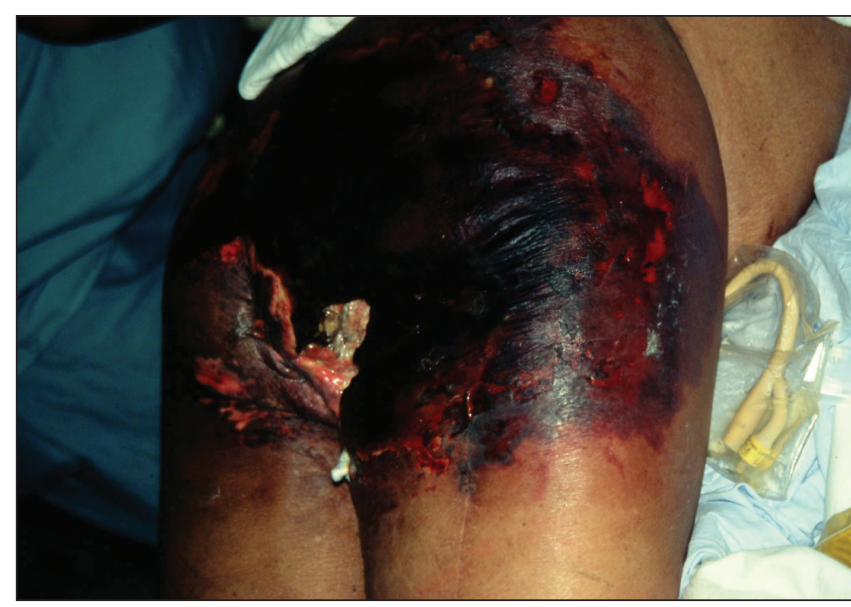

Figure 1) Case 1, necrosis of buttocks

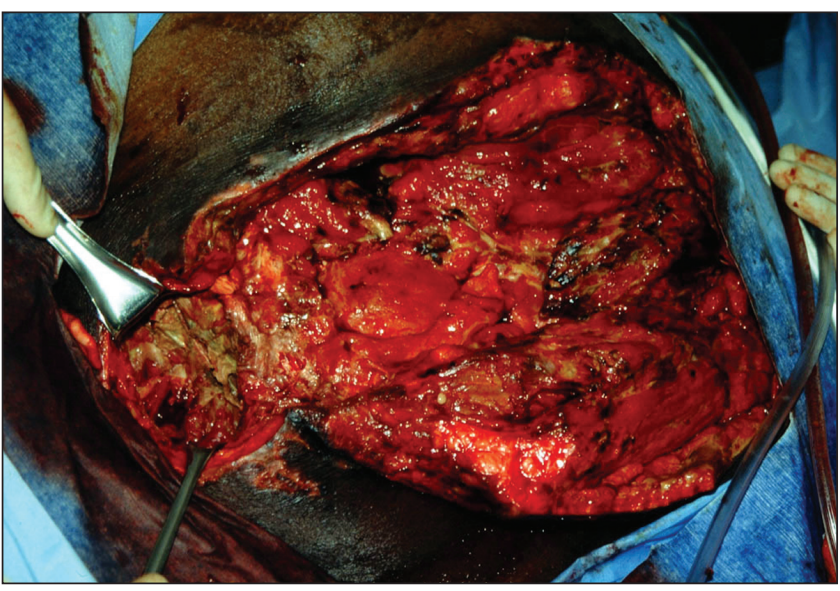

Figure 2) Case 1, following debridement

Department of Plastic Surgery, Wayne State University, Detroit, Michigan, USA

Correspondence: Dr C Balakrishnan, Division of Plastic Surgery, John Dingell Veterns Affairs Medical Center, 4646 John R, Detroit, Michigan 48201,USA.E-mail cbalakri@med.wayne.edu 


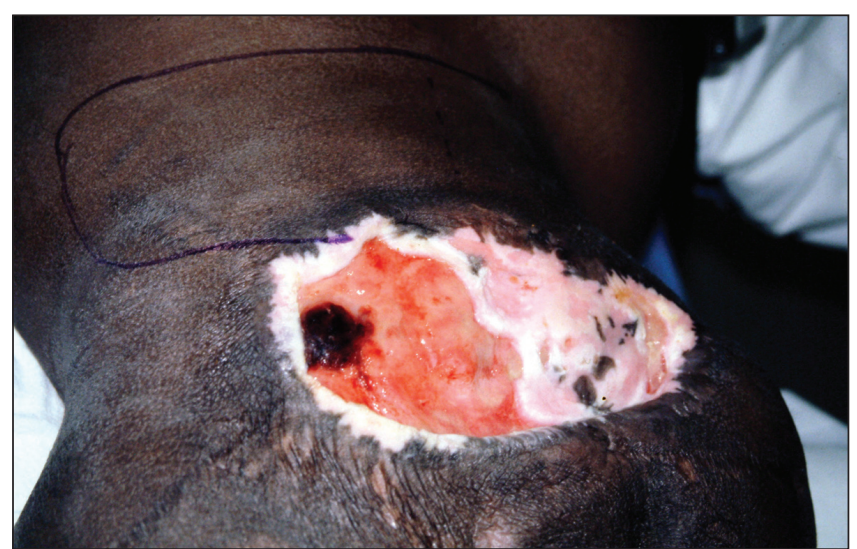

Figure 3) Case 1, at six months following vacuum-assisted closure

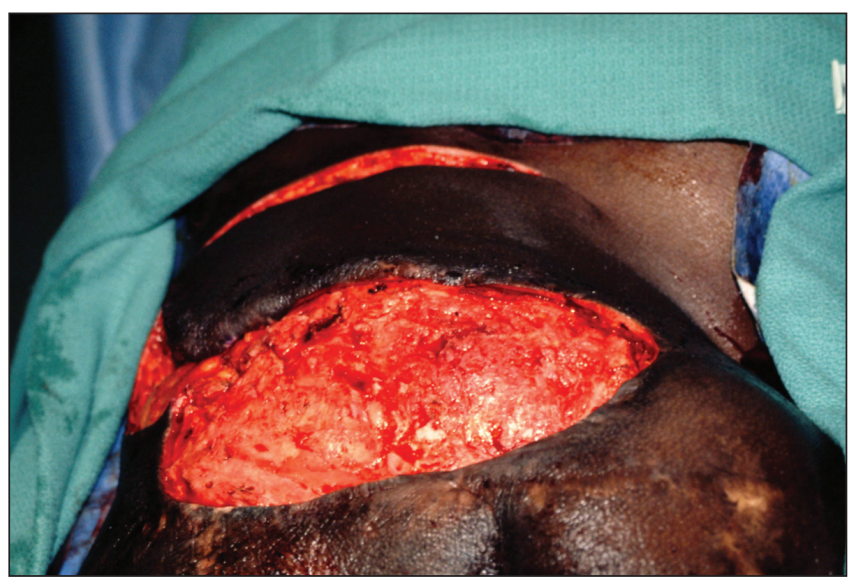

Figure 4) Case 1, flap elevated

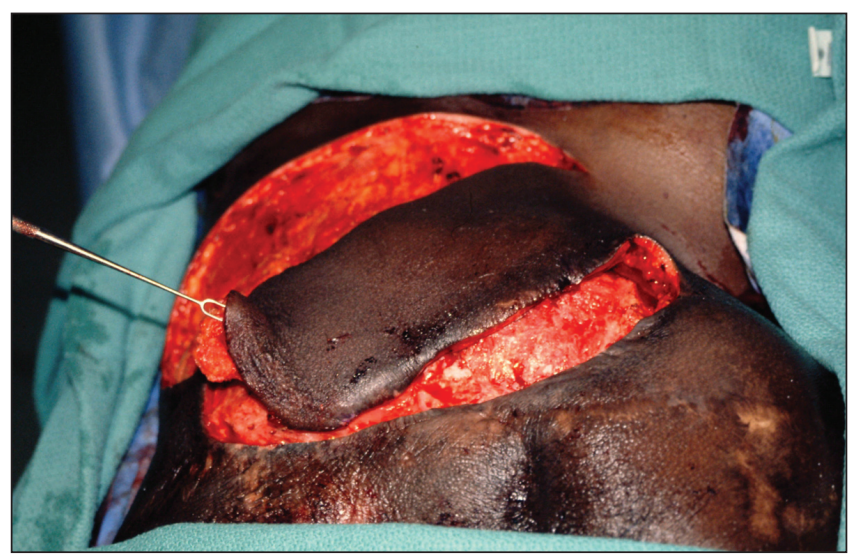

Figure 5) Case 1, flap transposed

\section{Case 2}

A 52-year-old man presented to the emergency department following a crush injury to his pelvis resulting from a motor vehicle accident. He was trapped under a car and had laceration to his scalp, abrasions to his left buttock and left thigh, and was hypotensive. He was paraplegic with no rectal tone and lacked sensation in both feet. He had no significant illness in the past. Trauma work-up showed a grade III 'open book' fracture of the pelvis. His chest $\mathrm{x}$-ray and spine series were negative for any fractures. He was alert and oriented. He underwent repair of his scalp laceration and was resuscitated. Because he was hypotensive even after stabilizing his pelvis, a decision was made to undertake selective angiography and

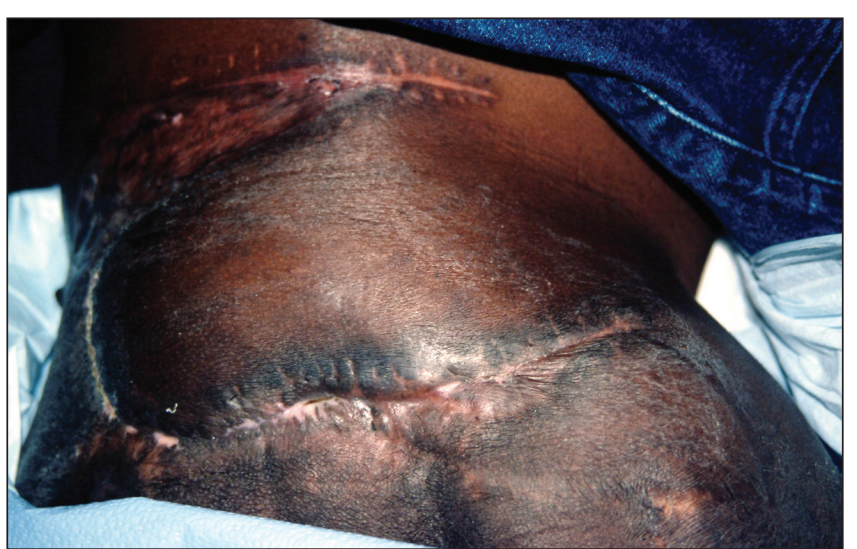

Figure 6) Case 1, final result

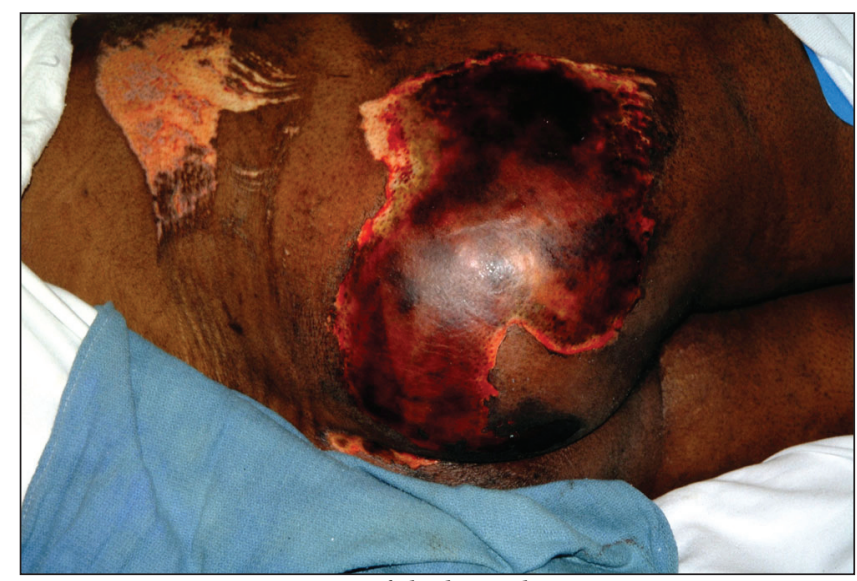

Figure 7) Case 2, Necrosis of the buttocks

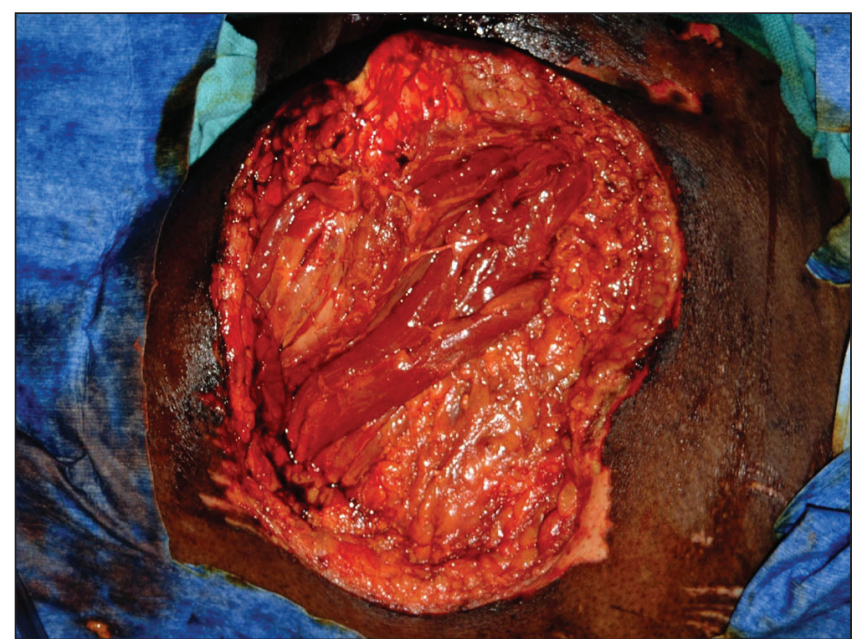

Figure 8) Case 2, following debridement

embolization. He underwent embolization of the internal iliac artery, which controlled his bleeding.

On the following day, it was noted that he had an area of necrosis of buttocks mainly on the right side, which progressed over the next $24 \mathrm{~h}$ (Figure 7). He underwent a colostomy and multiple debridements (Figure 8). He was initially treated with vacuum-assisted closure to obtain good granulation tissue (Figure 9). He underwent a transverse lumbar flap reconstruction the sacral defect (Figure 10) with staged skin grafting of the donor defect. His flap and skin grafting was stable at one year (Figure 11). 


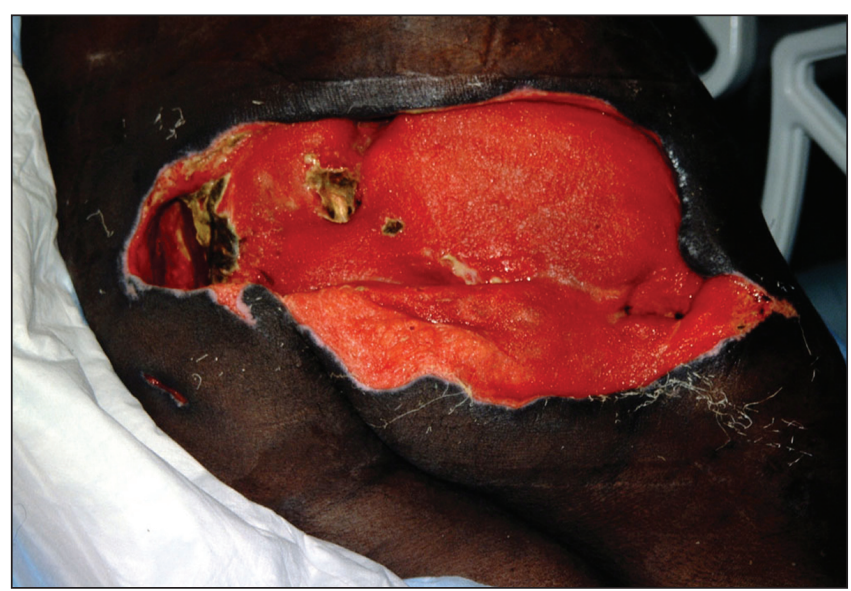

Figure 9) Case 2, granulating wound

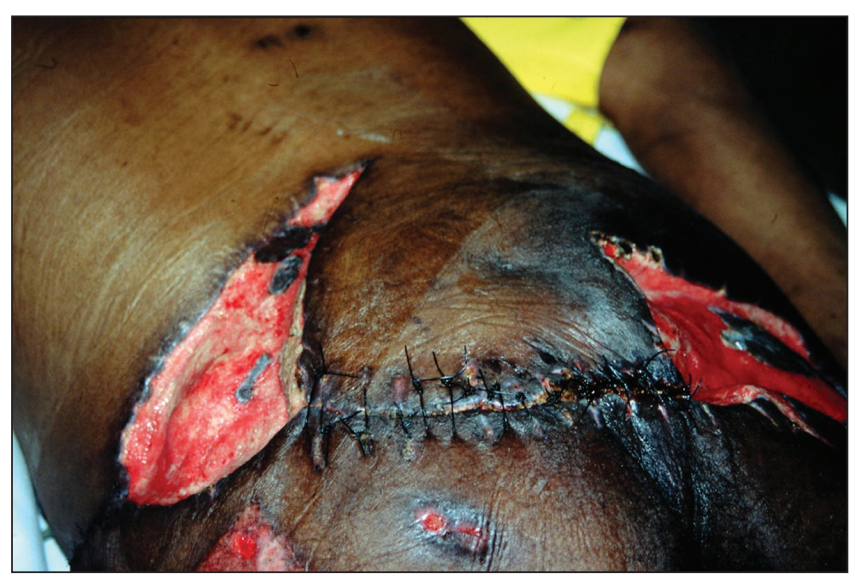

Figure 10) Case 2, transverse lumbar flap based on the right side in place

\section{DISCUSSION}

Knowledge of sites of ongoing hemorrhage is crucial for optimizing the sequence of diagnostic and therapeutic studies in patients with blunt trauma. Therefore, the importance of early angiography in multiple trauma patients with pelvic fractures and persistent hemorrhage is well established. Successful hemostasis can be achieved without complications by means of selective catheterization into each branch of the internal iliac artery. The interval to definite localization and treatment of the bleeding source was three times shorter in the group of survivors, and the amount of transfusions needed was less by a factor of three. Embolization has proven to be effective in the treatment of such injuries (1).

Transcatheter arterial embolization for pelvic fractures can cause gluteal skin and muscle necrosis. Initial traumatic contusion cannot be ruled out as contributing to the development of the necrosis (2). Buttock necrosis is a possible complication of nontarget embolization during uterine artery embolization (3).

Large lumbosacral defects remain a difficult challenge in reconstructive surgery, especially in the nonparaplegic patient. Traditional options for closure include local rotation or

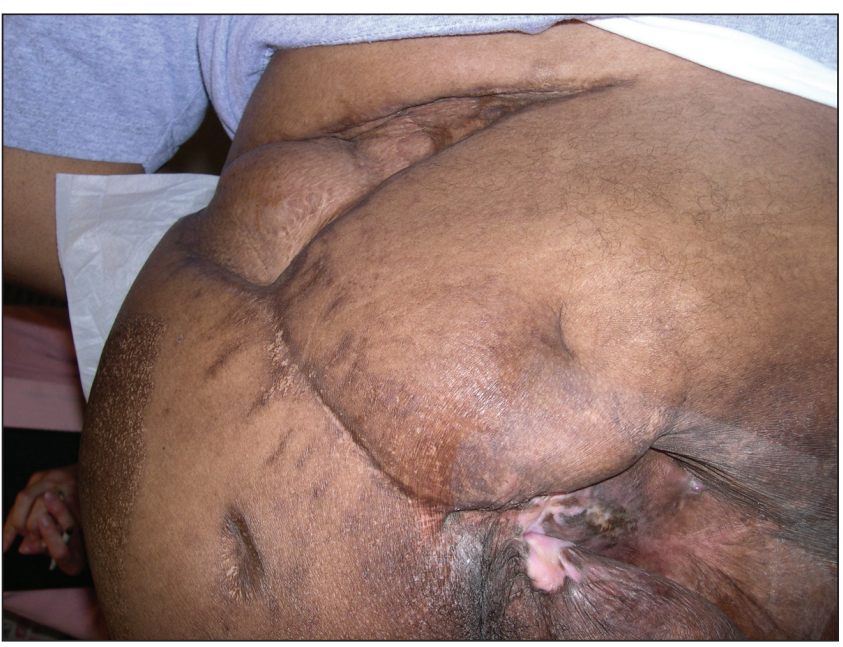

Figure 11) Case 2, Final result at one year

transposition flaps and musculocutaneous flaps. These flaps, however, are not an optimal option in previously irradiated or operated areas, or in cases of large defects. Using the transverse lumbar flaps based on the lumbar perforator vessels, minimal morbidity of the donor site is expected, because the donor defect is usually located in the lower back (4). The gluteus maximus is usually not viable due to embolization of the vascular pedicle. Cutaneous perforators derived from the lower intercostal arteries and lumbar perforators that penetrate the cutaneous territory can be used as vascular pedicles. These pedicled perforator flaps have been used to reconstruct large lumbosacral defects (5).

In our case series, the first patient was treated conservatively with vacuum-assisted wound closure. Because the healing process was slow, the wound was subsequently debrided and closed using a transverse lumbar flap, with good result. The second patient developed necrosis of the buttock following embolization of the internal iliac artery to control bleeding. The defect was treated with a transverse lumbar flap based on the right side, followed by internal fixation of the pelvic fracture. The transverse lumbar flap should be considered in patients with poor vascularity to the gluteal flaps.

\section{REFERENCES}

1. Hiki T, Okada Y, Wake K, Fujiwara A, Kaji Y. Embolization for a bleeding pelvic fracture in a patient with persistent sciatic artery. Emerg Radiol 2007;14:55-7.

2. Suzuki T, Shindo M, Kataoka Y, et al. Clinical characteristics of pelvic fracture patients with gluteal necrosis resulting from transcatheter arterial embolization. Arch Orthoped Trauma Surg 2005;125:448-52.

3. Dietz DM, Sthlfeld KR, Bansal SK, Christopherson WA. Buttock necrosis after uterine artery embolization. Obstetr Gynecol 2004;104:1059-61.

4. Rawat SS, Mathur BS. Transverse lumbar flap for sacral bed sores. Plast Reconstr Surg 1991;88:154-8.

5. Roche NA, Van Landuyt K, Blondeel PN, Matton G, Monstrey SJ. The use of pedicled perforator flaps for reconstruction of lumbosacral defects. Ann Plast Surg 2000;45:7-14. 